Abstract 133 Table 1 Comparison between mini-mitral and sternotomy approach

\begin{tabular}{|l|c|c|c|}
\hline \multicolumn{1}{|c|}{ Parameter } & $\begin{array}{c}\text { Mini-mitral approach } \\
(\mathrm{N}=66)\end{array}$ & $\begin{array}{c}\text { Sternotomy approach } \\
(\mathrm{N}=154)\end{array}$ & P value \\
\hline $\begin{array}{l}\text { Age (mean } \pm \text { SD) } \\
\text { [years] }\end{array}$ & $64.09 \pm 1.79$ & $69.23 \pm 0.84$ & $\mathbf{0 . 0 1 2}$ \\
\hline Female (N, \%) & 25 & 58 & 0.976 \\
\hline $\begin{array}{l}\text { NYHA class III and IV } \\
\text { (N, \%) }\end{array}$ & 33 & 50 & 0.860 \\
\hline $\begin{array}{l}\text { History of } \\
\text { MI/PCl/CABG (N, \%) }\end{array}$ & 6 & $79.63 \pm 2.75$ & 0.001 \\
\hline $\begin{array}{l}\text { EUROSCORE (mean } \\
\pm \text { SD) }\end{array}$ & $6.42 \pm 3.68$ & 44 & 0.169 \\
\hline $\begin{array}{l}\text { Concurrent tricuspid } \\
\text { valve annuloplasty } \\
(\mathrm{N}, \%)\end{array}$ & 13 & 41 & $\mathbf{0 . 0 1 8}$ \\
\hline $\begin{array}{l}\text { Urgent surgery (N, } \\
\%)\end{array}$ & 18 & 27 & 0.101 \\
\hline $\begin{array}{l}\text { RV impairment (N, } \\
\%)\end{array}$ & $51.7 \pm 5.4$ & $49.4 \pm 8.3$ & 0.816 \\
\hline $\begin{array}{l}\text { LV EF (\%) (mean } \pm \\
\text { SD) }\end{array}$ & & & \\
\hline
\end{tabular}

Abstract 133 Table 2 Comparison between patients with RV impairment versus preserved RV function

\begin{tabular}{|l|c|c|c|}
\hline Parameter & $\begin{array}{c}\text { RV impairment } \\
(\mathrm{N}=45)\end{array}$ & $\begin{array}{c}\text { No RV impairment } \\
(\mathrm{N}=175)\end{array}$ & P value \\
\hline $\begin{array}{l}\text { Age (mean } \pm \text { SD) } \\
\text { [years] }\end{array}$ & $67.0 \pm 12.9$ & $67.9 \pm 11.8$ & 0.881 \\
\hline Female (N, \%) & 12 & $84(48)$ & 0.086 \\
\hline $\begin{array}{l}\text { NYHA class III and IV } \\
\text { (N, \%) }\end{array}$ & $28(62)$ & $46(26)$ & 0.089 \\
\hline $\begin{array}{l}\text { History of } \\
\text { MI/PCI/CABG (N, \%) }\end{array}$ & $10(22)$ & $7.3 \pm 3.1$ & 0.881 \\
\hline $\begin{array}{l}\text { EUROSCORE (mean } \\
\pm \text { SD) }\end{array}$ & $7.2 \pm 3.2$ & $42(24)$ & 0.817 \\
\hline $\begin{array}{l}\text { Concurrent tricuspid } \\
\text { valve annuloplasty } \\
(\mathrm{N}, \%)\end{array}$ & $15(33)$ & 61 & 0.202 \\
\hline $\begin{array}{l}\text { Concurrent CABG } \\
(\mathrm{N}, \%)\end{array}$ & 16 & $41(23)$ & 0.930 \\
\hline $\begin{array}{l}\text { Urgent surgery (N, } \\
\%)\end{array}$ & $8(18)$ & $50.4 \pm 7.4$ & 0.198 \\
\hline $\begin{array}{l}\text { LV EF (\%) (mean } \pm \\
\text { SD) }\end{array}$ & $48.9 \pm 8.5$ & & \\
\hline
\end{tabular}

\section{CLINICAL PREDICTORS OF INFORMATIVE GENETIC TESTING IN PATIENTS WITH HYPERTROPHIC CARDIOMYOPATHY (HCM)}

${ }^{1}$ Amjad Ghazal Asswad, ${ }^{1}$ Akriti Naraen*, ${ }^{2}$ Timothy Fairbairn, ${ }^{2}$ Simon Modi, ${ }^{2}$ Matthew Shaw, ${ }^{2}$ John Somauroo, ${ }^{2}$ Rod Stables, ${ }^{2}$ Derick Todd, ${ }^{2}$ Victoria McKay, ${ }^{3}$ Rob Cooper. ${ }^{1}$ Institute of Cardiovascular Medicine and Science, Liverpool Heart and Chest Hospital; ${ }^{2}$ Liverpool Heart and Chest Hospital; ${ }^{3}$ Institute of Cardiovascular Medicine and Science, Liverpool Heart and Chest Hospital

\subsection{6/heartjnl-2019-BCS.131}

Background HCM is a disease characterised by otherwise unexplained hypertrophy of the myocardium, often as a result of a gene mutation. Phenotypic expression is estimated at 1 in
500 and genetic prevalence at 1 in 200. Genetic testing is used primarily to facilitate predictive testing in family members.

Method A retrospective analysis of 174 consecutive HCM patients undergoing diagnostic genetic testing at a tertiary referral service in Liverpool, UK (January 2014 - February 2019) was performed. Univariate and multivariate analysis was performed on pre-defined clinical characteristics. Left ventricular morphology was assessed using echocardiography and cardiac MRI. Morphology was categorised into five groups: reverse curve, sigmoid, apical, concentric and focal. Standard HCM panels were performed via Oxford and Royal Brompton genetic laboratories. Class 4 and 5 variants were deemed 'informative'. 
Results 72/174 (41.4\%) genetic tests were informative. Those with informative tests were younger, with a mean age of 48.9 (confidence interval (CI) 45.5-52.3). Those with uninformative results had a mean age of 54.6 (CI 52.1-57.1) There was a higher incidence of positive Family History (FH) for HCM or sudden cardiac death (SCD) $(43.1 \%$ vs $20.6 \%, p=0.002)$ in those with informative tests. Reverse curve morphology of the septum was seen in $70.8 \%$ of informative tests.

Multivariate analysis demonstrated that reverse curve morphology (Odds ratio (OR) 2.85, CI 1.45-5.57, p=0.002), FH of SCD/HCM (OR 2.18, CI 1.07-4.42, p=0.031) and younger age at time of testing (OR 0.97, CI 0.94-0.99, $\mathrm{p}=0.007)$ were predictive of an informative test.

Univariate analysis demonstrated that maximum wall width, $\mathrm{T}$ wave inversion on ECG and non-sustained VT on ambulatory ECG were not predictive of an informative test $(n=125)$.

An informative test was seen in $75.0 \%(12 / 16)$ of patients with all 3 predictors of age $<50, \mathrm{FH} \mathrm{HCM} / \mathrm{SCD}$ and reverse curve morphology. If 2 of 3 factors were seen, the chance of an informative test fell to $63.8 \%(30 / 47), 1$ factor $=29.9 \%$ $(23 / 77)$ and 0 factors $=20.6 \%$ (7/34). Patients with reverse curve morphology had informative genetic tests in $54.3 \%$ of cases (51/94) regardless of age at presentation.

Those with an informative test were more likely to have an ICD. Of the 72 informative results, 26 had an ICD implanted compared with 20/102 with uninformative results (36.1\% vs $19.6 \%, \mathrm{p}=0.022)$.

Variants in MYBPC3 were the most frequent accounting for 39 of the $72(54.2 \%)$. MYH7 accounted for 17 cases (23.6\%), TNNI3 for $4(5.6 \%), \quad F L N C=3$ (4.2\%), GLA=2

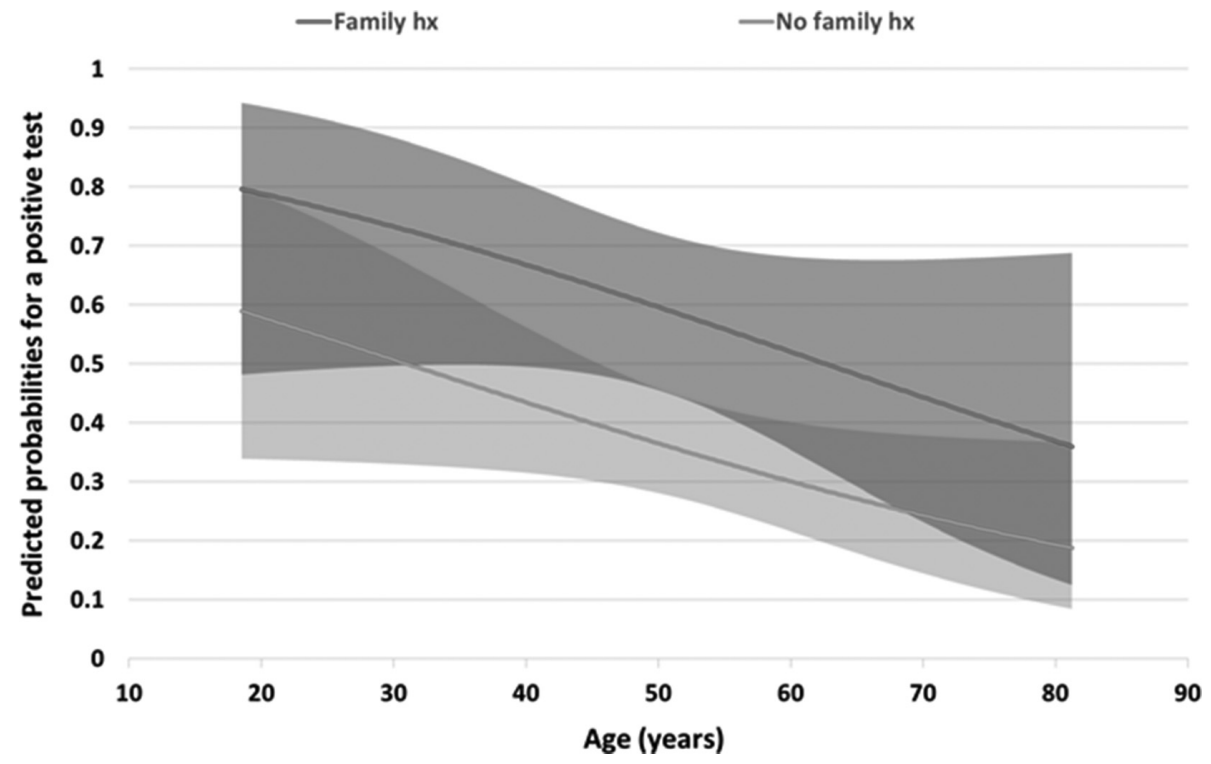

\section{Abstract 134 Figure 1}

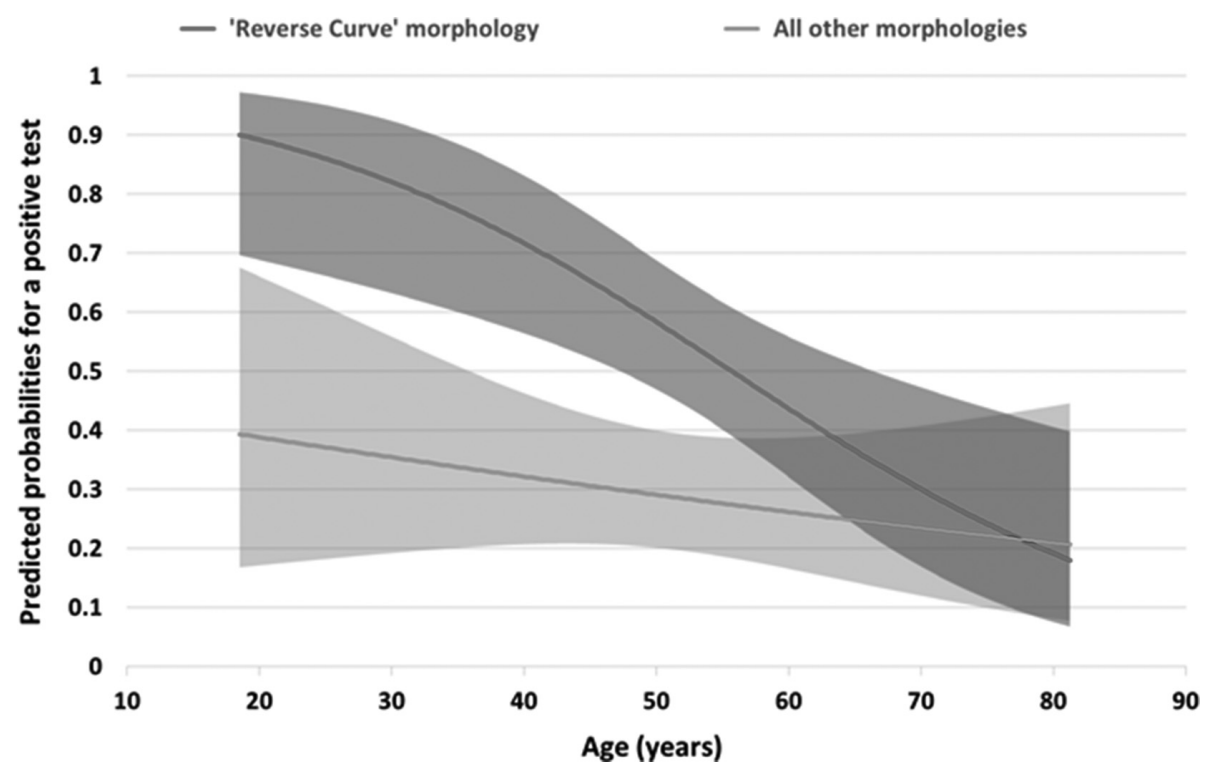


Abstract 134 Table 1 Multivariate regression analysis using predefined clinical characteristics

\begin{tabular}{|l|c|c|}
\hline & $\begin{array}{c}\text { Odds Ratio } \\
\mathbf{( 9 5 \% ~ C l )}\end{array}$ & P value \\
\hline Age at diagnosis (years) & $0.97(0.94,0.99)$ & 0.007 \\
\hline FH of SCD or HCM & $2.18(1.07,4.42)$ & 0.031 \\
\hline Reverse Curve & $2.85(1.45,5.57)$ & 0.002 \\
\hline
\end{tabular}

Abstract 134 Table 2 The likelihood of an informative test using a predictive model

\begin{tabular}{|c|c|}
\hline \multicolumn{1}{|c|}{ No. Factors } & Likelihood of positive result (\%) \\
\hline $3 / 3$ & 75.0 \\
\hline $2 / 3$ & 63.8 \\
\hline $1 / 3$ & 29.9 \\
\hline $0 / 3$ & 20.6 \\
\hline
\end{tabular}

Factors: Age $<50$, FH SCD/HCM, reverse curve septal morphology

$(2.8 \%), \quad$ ACTC1 $=2 \quad(2.8 \%), \quad$ TNNT2 $=2 \quad(2.8 \%), \quad$ MYL2 $=1$ $(1.4 \%)$, MYL3 $=1(1.4 \%)$ and TPM1 $=1$ (1.4\%).

Conclusion Reverse curve morphology of the septum (OR 2.85, CI 1.45-5.57), FH of SCD or HCM (OR 2.18, CI 1.07-4.42) and younger age at testing (OR 0.97, CI 0.940.99), are predictors of informative genetic testing in HCM, especially when two or more of these variables occur simultaneously (Table 1).

Conflict of Interest None

\section{REAL WORLD OUTCOMES FOR "INTERMEDIATE-HIGH" MORTALITY RISK PATIENTS PRESENTING WITH SUBMASSIVE PULMONARY EMBOLISM IN A TERTIARY CARDIOTHORACIC CENTRE}

${ }^{1}$ Paul Brennan*, ${ }^{2}$ Jaimie Coburn, ${ }^{2}$ Dean Carolan, ${ }^{2}$ Mark Spence, ${ }^{3}$ Timothy Warke ${ }^{3}$ Kathy Cullen, ${ }^{3}$ Julian Leggett, ${ }^{2}$ Nicola Johnston, ${ }^{2}$ Damian McCall, ${ }^{2}$ Ganesh Manoharan. ${ }^{1}$ Royal Victoria Hospital Belfast; ${ }^{2}$ Cardiology; ${ }^{3}$ Respiratory

10.1136/heartjnl-2019-BCS.132

Background Thrombolysis is an established recommended therapy for patients presenting with acute pulmonary embolism (PE) and shock. The management of "intermediate-high" risk patients is not as clear and the use of thrombolysis splits opinion and as such it remains a "consideration" for these patients in both the ESC and BTS guidelines. Both efficacy and safety of thrombolysis in this patient group have been variable in the major studies.

Aim sWe aimed to report real-world outcomes for all patients coded with a diagnosis of "intermediate-high" PE (SBP $>90 \mathrm{mmHg}$ without a drop in SBP of $>40 \mathrm{mmHg}$, but evidence of right ventricular (RV) strain and/or cardiac biomarker rise) in our hospital between January 2016 and December 2017.

Methods Baseline characteristics, clinical and echocardiographic outcomes were obtained, via clinical note review and Northern Ireland Electronic Care Record.
Results 41 patients (mean age $65+-14$ years, female sex $59 \%)$ met the diagnosis criteria. 25\% patients had an active/ prior cancer diagnosis, $30 \%$ had a prior VTE/PE and the lead symptom at presentation was dyspnoea in $89 \%$ patients. Cardiac arrest was the initial presentation for 2 patients. All patients had a cardiac biomarker rise (mean troponin T-hs $121.67+-304$ ng/L, mean NTpro-BNP $1666+-2313$ ng/L). $75 \%$ patients had a TTE performed acutely and RV systolic dysfunction/strain were seen in $63 \%$ patients, while $46 \%$ patients had an RVSP $>40 \mathrm{mmHg}$ (mean RVSP 51 +$22 \mathrm{mmHg})$.

$16 \%(n=3$, all had severe RV systolic dysfunction \& RVSP $>40 \mathrm{mmHg}$ ) patients received IV thrombolysis (Alteplase) and no patients had percutaneous therapy. 2 patients had an absolute contraindication to lysis agents. All of the lysed patients survived to discharge while $5 \%(n=2)$ of the non-lysed patients died as inpatients. No patients in either group required vasopressors, inotropes or mechanical ventilation. Major bleeding occurred only in the lysis group (33\%, $\mathrm{n}=1$ ) while minor bleeding occurred only in the non-lysed group (8\%, $n=3$, all non-intracranial). Non-haemorrhagic stroke wasn't seen and there were no allergic reactions to Alteplase.

At 30 days, 1 lysed patient had an extracranial major bleed, and mortality, only seen in non-lysed patients, was $8 \%$.

1-year mortality for lysed and non-lysed patients was $0 \%$ and 16\% (all non-PE/cardiac-related) respectively. 39\% patients had a recurrent VTE/PE event on anticoagulation. 23 patients (3 lysed, 20 non-lysed) had a repeat TTE performed (median time to diagnosis 120days) in whom evidence of possible chronic thromboembolic hypertension (CTEPH, (RVSP $>40 \mathrm{mHg})$ ) and/or RV systolic dysfunction was present in $67 \%(n=2)$ of lysed and $20 \%(n=4)$ non-lysed patients respectively.

Conclusion sIV PE lysis was administered safely and effectively in a small group of selected PE patients with severe RV systolic dysfunction and biomarker rise. The lack of cardiac mortality at 1 year in those not lysed, alongside the modest freedom from potential CTEPH, is reassuring. Further study is required to correctly allow for prediction of patients that will benefit from IV thrombolysis for submassive PE.

Conflict of Interest None

\section{SAME-DAY ADMISSION FACILITATED BY A NURSE LED PATHWAY REDUCES HOSPITAL LENGTH OF STAY FOR TRANSFEMORAL TRANSCATHETER AORTIC VALVE IMPLANTATION}

${ }^{1}$ Gemma MCCALMONT, ${ }^{2}$ Paul Williams, ${ }^{3}$ Douglas Muir, ${ }^{4}$ Bilal Bawamia, ${ }^{5}$ Muhammad Arshad. ${ }^{1}$ South Tees Hospitals NHS Foundation Trust; ${ }^{2}$ South Tees Hospitals NHS Foundation Trust; ${ }^{3}$ South Tees Hospitals NHS Foundation Trust; ${ }^{4}$ South Tees Hospitals NHS Foundation Trust; ${ }^{5}$ South Tees Hospitals NHS Foundation Trust

\subsection{6/heartjnl-2019-BCS.133}

Background There is a growing interest in reducing the hospital length of stay for patients undergoing transcatheter aortic valve intervention (TAVI), with particular focus on patients 